\title{
A TEORIA CRÍTICA DA SOCIEDADE E A EDUCAÇÃO PARA A FORMAÇÃO HUMANA: PONTUAÇÕES PARA SE REPENSAR OS PROCESSOS FORMATIVOS NA PERSPECTIVA EMANCIPATÓRIA
}

\author{
Estelamaris Brant Scarel *
}

\begin{abstract}
Resumo: As análises elaboradas pelos pensadores frankfurtianos Adorno e Horkheimer, a partir da obra "Dialética do Esclarecimento" (1985), com referência à promessa de iluminação da razão, que, contraditoriamente, transformou-se em um malogro, em virtude de as relações entre os homens em sociedade pautarem-se pelo viés da racionalidade científico-instrumental, levaram o presente texto a deter-se em três objetivos específicos. Primeiramente, ele procura trazer à tona alguns elementos fundamentais contidos na obra acima aludida, os quais possibilitam o entendimento de que a limitação da filosofia pela sua rendição à ciência se deve, principalmente, à fragilização da capacidade reflexiva. Em segundo lugar, busca fazer uma aproximação aos conceitos de educação, formação e experiência formativa, tentando, simultaneamente, apreender os nexos que conduziram à ruptura, na modernidade, entre sujeito e objeto, universal e particular, teoria e práxis. Em terceiro e último lugar, põe em relevo os desafios postos à educação contemporânea no que concerne à premência de ela recuperar o processo formativo, mediante o desenvolvimento de uma educação para a experiência, por conseguinte, para a emancipação.
\end{abstract}

Palavras-chave: Teoria Crítica, Educação, Formação, Emancipação.

Resumen: Los análisis elaborados por los pensadores frankfurtianos Adorno y Horkheimer, a partir de la obra "Dialéctica de Aclaración" (1985), con referencia a la promesa de iluminación de la razón, que, contradictoriamente, se transformó en un fracaso, en virtud de que las relaciones entre los hombres en sociedad se rigen por el sesgo de la racionalidad científico-instrumental, lo cual llevó al presente texto a detenerse en tres objetivos específicos. En primer lugar, intenta traer a la luz algunos elementos fundamentales contenidos en la obra aludida anteriormente, los cuales posibilitan el entendimiento de que la limitación de la filosofía por su rendición a la ciencia se debe, principalmente, a la fragilización de la capacidad reflexiva. En segundo lugar, trata de hacer una aproximación a los conceptos de educación, formación y experiencia formativa, intentando al mismo tiempo aprehender los nexos que condujeron a la ruptura, en la modernidad, entre sujeto y objeto, universal y particular, teoría y praxis. En tercer y último lugar, pone de relieve los retos a la educación contemporánea en lo que concierne a la premura de recuperar el proceso formativo, mediante el desarrollo de una educación para la experiencia, por consiguiente, para la emancipación.

Palabras claves: Teoría Crítica, Educación, Formación, Emancipación.

\footnotetext{
" Doutora em Educação pela Universidade Federal de Goiás. Professora da Pontifícia Universidade Católica de Goiás - PUC Goiás.
}

SCAREL, Estelamaris Brant. A Teoria Crítica da Sociedade e a Educação para a Formação Humana: pontuações para se repensar os processos formativos na perspectiva emancipatória. Revista SulAmericana de Filosofia e Educação. Número 29: nov./2017-abr./ 2018, p. 56-70. DOI: https://doi.org/10.26512/resafe.v0i29.21006 


\section{A Dialética do Esclarecimento e a Sujeição da Filosofia à Racionalidade Científico- Instrumental}

A crítica à racionalidade moderna transformou-se numa das questões fundamentais para a Teoria Crítica da Sociedade. Isso se constata em todas as reflexões realizadas pelos teórico-críticos frankfurtianos. Por exemplo, ao lançar-se o olhar para dois dos primeiros trabalhos realizados por Adorno, que são "A Atualidade da Filosofia" (1991 a) e "A Ideia de História Natural” (1991b), já se detecta tal posicionamento crítico. No que tange à primeira produção, esta diz respeito à aula inaugural proferida por este filósofo na Faculdade de Filosofia da Universidade de Frankfurt, em 7 de maio de 1930, quanto à segunda, esta ocorreu um ano após, por intermédio de uma conferência, também, realizada na mesma Universidade. Ambos os trabalhos tinham uma preocupação em comum, isto é, indicar as contradições presentes na filosofia moderna, seja com a sua recaída no idealismo, seja com o seu rigoroso aprofundamento na ontologização, culminando por levar à cisão "ser natural $e$ histórico" (SCAREL, 2016). Em contraposição a esta perspectiva, Adorno (1991 b) afirma que a ontologia não deveria tentar encontrar
[...] um ser puro, subjacente ao ser histórico, ou que se encontraria nela, e sim compreender o próprio ser histórico como ontológico, isto é, como ser natural. Transformar assim em sentido inverso a história concreta em natureza dialética é a tarefa da ontológica mudança de orientação da filosofia da história: a ideia de história natural (ADORNO, 1991 b, p. 118).

Entretanto, é preciso que se explicite que a crítica às insuficiências da filosofia moderna não se restringe somente a Adorno, pelo contrário, ela também se faz presente nas reflexões elaboradas por outros pensadores da Teoria Crítica especialmente Horkheimer, (1991 a, 1991 ) Benjamin (1994) e Marcuse (1967), embora reitera-se que neste artigo privilegiar-se-á as análises feitas pelos dois primeiros filósofos. Referentemente a Horkheimer, o embate contra a ideologia enraizada na racionalidade burguesa já se encontra latente desde os seus ensaios da década de 1930. No texto "Teoria Tradicional e Teoria Crítica" (1991 a), por exemplo, este frankfurtiano, partindo da distinção entre estas duas concepções, aponta a perspectiva cartesiana como o modelo 
identificador da racionalidade moderna, paradigma este que se centra numa visão abstracionista e técnico-científica da realidade, que, em consequência, termina por causar a separação entre sujeito $e$ objeto, teoria e práxis, universal e particular. Com efeito, uma concepção científica

[...] que em sua autonomia imaginária se satisfaz em considerar a práxis - à qual serve e na qual está inserida - como seu Além, e se contenta com a separação entre pensamento e ação, já renunciou à humanidade $\quad[\ldots] \quad \mathrm{A}$ autodeterminação da ciência se torna cada vez mais abstrata. $\mathrm{O}$ conformismo do pensamento, a insistência em que isto constitua uma atividade fixa, um reino à parte dentro da totalidade social, faz com que o pensamento abandone a sua própria essência (HORKHEIMER, 1991a, p. 68).

Contudo, o questionamento tanto concernente à idealização da práxis como à racionalização da filosofia, por meio da ciência, não se esgota aí. No ensaio denominado "Filosofia e Teoria Crítica" (1991b), publicado pela primeira vez em 1937 na Revista para a Pesquisa Social (Zeitschrift fuer Sozialforschung),
Horkheimer, dando sequência à crítica iniciada no ensaio "Teoria Tradicional $e$ Teoria Crítica" (1991 a), expõe não somente a marca distintiva desta concepção teórica, mas, sobretudo, assinala qual deve ser a tarefa essencial da filosofia. E, assim, ele faz o seguinte esclarecimento:

\begin{abstract}
A teoria crítica da sociedade [...] tem como objeto os homens como produtores de todas as suas formas históricas de vida. As situações efetivas, nas quais a ciência se baseia, não é para ela uma coisa dada, cujo único problema estaria na mera constatação e previsão segundo as leis da probabilidade. $\mathrm{O}$ que é dado não depende apenas da natureza, mas também do poder do homem sobre ela. Os objetos e a espécie de percepção, a formulação de questões e o sentido da resposta dão provas da atividade humana e do grau de seu poder (HORKHEIMER, 1991 b, p. 69).
\end{abstract}

Para este autor, é exatamente em face de esta concepção ligar-se à previsibilidade, à formalização $e$ à mecanização que ela culmina por estabelecer o distanciamento da filosofia de sua tarefa crítica e emancipatória, em virtude de ela inclinar-se para o reino da 
equivalência, da quantificação bem como, ainda, da transformação da natureza num mundo abstrato. Isso terá consequências dramáticas para a convivência humana, pois, a partir dessa visão objetiva da realidade, as relações entre os homens tornam-se cada vez mais racionalizadas $e$ pragmáticas, resultando, dessa maneira, na equiparação entre homens e coisas. É este processo de "desencantamento do mundo", que, consoante Adorno; Horkheimer (1985), corresponde ao ceifamento do "animismo", da magia, contraditoriamente, ao invés de possibilitar o esclarecimento termina por conduzir a realidade social à ausência de tensionamento, porquanto administrada por uma racionalidade que a tudo mantém sob o seu domínio, levando o mundo, por um lado, à derrocada do mito, mas, por outro, a perda de sentido.

$\mathrm{O}$ mito converte-se em esclarecimento, e a natureza em mera objetividade. O preço que os homens pagam pelo aumento de seu poder é a alienação daquilo sobre o que exercem $\mathrm{o}$ poder. $\mathrm{O}$

\footnotetext{
${ }^{1}$ Não obstante Max Weber haver recebido críticas dos frankfurtianos, por exemplo, por parte de Adorno (2009) e por Marcuse (1968), este conceito foi tomado como empréstimo por estes autores a partir das análises weberianas contidas na obra "A Ética Protestante e o Espírito do Capitalismo" (1989).
}

esclarecimento comporta-se com as coisas como o ditador se comporta com os homens. Este conhece-os na medida em que pode manipular. O homem de ciência conhece as coisas na medida em que pode fazê-las. É assim que seu 'em-si torna para-ele'. Nessa metamorfose, a essência das coisas revela-se como sempre a mesma, como substrato da dominação. Essa identidade constitui a unidade da natureza (ADORNO; HORKHEIMER, 1985, p. 24; grifo no original).

Mas, se, por uma via, sob o manto ideológico da lógica formal e, também, da aparente neutralidade, a ciência se transforma no guia seguro para o homem moderno, por outra, segundo já se afirmou, este mesmo homem vê-se envolto em um processo de alheamento mediante à sua sujeição à lógica da adaptação e da ausência de autonomia frente ao império da calculabilidade, por conseguinte, da sua sucumbência ao esquema da uniformização. "Quem fica privado da esperança não é a existência, mas o saber que no símbolo figurativo ou matemático se apropria da existência enquanto esquema $e$ a perpetua como tal" (ADORNO; HORKHEIMER, 1985, p. 39).

Mais de sete décadas separam a afirmação acima, a qual se encontra na obra "Dialética do Esclarecimento" (1985), 
publicada em 1944, da realidade atual, e o que se constata é que em lugar de essa crença de cunho mecanicista ceder a uma visão mais totalizante da realidade, pelo contrário, ela recrudesce-se, levando os indivíduos a professarem incondicionalmente o seu credo a essa perspectiva que, de forma gradativa, foi potencializando o seu poder dominador $e$ cerceador da liberdade de pensamento $e$, consequentemente, de ação. Para Adorno; Horkheimer (1985):

A subjetividade volatizou-se na lógica de regras de jogo pretensamente indeterminadas, a fim de dispor de uma maneira ainda mais desembaraçada [...] A expulsão do pensamento da lógica ratifica na sala de aula a coisificação do homem na fábrica $e$ no escritório [...] $\mathrm{O}$ eu integralmente capturado pela civilização se reduz a um elemento dessa inumanidade, à qual a civilização desde o início procurou escapar (ADORNO; HORKHEIMER, 1985, p. 41-42).

Pode-se inferir, a partir disso, que quanto mais o homem resvala nessa "inumanidade" mais ele recai na barbárie. A barbárie consiste na tendência à regressão ${ }^{2}$ institual, freudianamente

\footnotetext{
${ }^{2}$ No seu sentido 'temporal', a regressão supõe uma sucessão genética e designa o retorno do sujeito a
}

expressando, e que, segundo a concepção de Adorno (1995), é definida da seguinte maneira:

Entendo por barbárie algo muito
simples, ou seja, que, estando na
civilização do mais alto
desenvolvimento tecnológico, as
pessoas se encontrem atrasadas de
um modo peculiarmente disforme
em relação à sua própria civilização
- e não apenas por não terem em
sua arrasadora maioria
experimentado a formação nos
temos correspondentes ao conceito
de civilização, mas também por se
encontrarem tomadas por uma
agressividade primitiva, um ódio
primitivo, que contribui para
aumentar ainda mais o perigo de
que toda esta civilização venha a
explodir, aliás uma tendência
imanente que a caracteriza
(ADORNo, 1995, p. 155).

Diante desta elucidativa explicação a respeito de tal paradoxo, as perguntas que se impõem são estas: como é possível, na realidade atual, confrontar uma perspectiva tão contraditória? Até que ponto a educação, a formação e a experiência formativa seriam capazes de travar o combate com vistas ao empalidecimento dessa visão pragmatizada, isto é,

etapas ultrapassadas do seu desenvolvimento (fases libidinais, relações de objeto, identificações, etc.) (LAPLANCHE; PONTALIS, Op. cit., p. 440). 
"rigidamente

funcionalizada", configurando-se, em outras palavras, na "racionalidade instrumental", segundo Adorno; Horkheimer (1985)? São estas questões que se procurará compreender a seguir, evidentemente, considerando os limites trazidos por este artigo.

Sobre a Educação, a Formação e Experiência Formativa: apontamentos no sentido da formação humana sob o prisma educativo emancipatório

As discussões elaboradas até aqui evidenciaram que a limitação na qual a filosofia recaiu em face de sua rendição à ciência se deve, principalmente, à fragilização da capacidade reflexiva. Este foi um dos pontos cruciais abordados pela "Dialética do Esclarecimento" (1985). Para os autores desta obra, o "progresso irrefreável" e a redução de tudo a um denominador comum causou danos em profundidade tanto à capacidade de o homem realizar experiências intelectuais, como, também, teve implicações decisivas no "[...] intelecto autocrático, que se separa da experiência sensível para submetê-la" (ADORNO; HORKHEIMER, 1985, p. 46-47). Ora, deduz-se, a partir disso, que esta separação entre conhecimento e realidade ou, de outra forma, entre sujeito e objeto acaba tendo consequências inimagináveis à formação dos indivíduos, uma vez que a formação cultural (Bildung) requer o vínculo entre "objeto e reflexão" (ADORNO, 1995, p. 63). Não obstante esta exigência ser inerente à formação cultural tem-se que reconhecer que, sob o comando dos elementos padronizadores engendrados pela lógica dominadora socioeconômica $e$ científica, tal possibilidade é negada. Dessa maneira, a razão termina por ser reduzida a um mero apêndice dos processos antihumanizadores. Em síntese:

\begin{abstract}
A unificação da função intelectual, graças à qual se efetua a dominação dos sentidos, a resignação do pensamento em vista da produção da unanimidade, significa o empobrecimento do pensamento bem como da experiência [...] O espírito torna-se de fato o aparelho da dominação $e$ do auto-domínio, como sempre havia suposto erroneamente a filosofia burguesa (ADORNO; HORKHEIMER, 1985, p. 47).
\end{abstract}

Premidos pela lógica da técnica, os homens anseiam tornarem-se libertos da experiência e entregarem-se de bom grado à novidade. Dessa forma, diante do império da natureza e da técnica, o homem torna-se cativo. Assim, entregue às inúmeras 
exigências cotidianas e preso a instâncias débeis e primárias, ele se satisfaz apenas com o imediatamente dado. Em outras palavras: "A natureza e a técnica, o primitivismo e o conforto se unificam completamente e, então, [...] surge uma existência que se basta a si mesma" (BENJAMIN, 1994, p. 119). É isso que este frankfurtiano denomina de "pobreza de experiência". Mas afinal como se processa a experiência?

A experiência exige a unidade da consciência. $\mathrm{O}$ 'eu penso' tem que 'poder' acompanhar todas as minhas representações; pois, do contrário, seria representado em mim algo que não poderia de modo algum ser pensado, o que equivale a dizer que a representação seria impossível ou, pelo menos para mim, não seria nada (KANT, 1996, p. 121).

Com efeito, uma consciência que se habitua a representar o que já se encontra pronto e acabado, isto é, o dado, está desprovida da capacidade de realização da autorreflexão crítica, pois, conforme já exposto, o sujeito está separado do objeto. Se se rompe este vínculo joga-se para o limbo a tensão, está-se, por conseguinte, aberto o caminho para a entrada $e$ permanência da pseudoformação
(Halbbildung). Para Adorno (2004), sob o comando da pseudoformação as consciências se tornam niveladas, persistindo, dessa maneira, “[...] os conteúdos objetivos coisificados, com caráter de mercadoria da educação ao preço de seu conteúdo de verdade de sua relação com sujeitos vivos" (ADORNO, 2004, p. 95). Diante desta constatação aterradora, entende-se que a recuperação da experiência formativa passa a configurar-se numa condição sine qua non. Em razão disso, a educação com vistas ao esclarecimento transforma-se em uma condição imperante em quaisquer processos formativos. Tal empreendimento deveria ter como ponto de partida o combate à razão instrumental, arquitetada pela Indústria Cultural, que a tudo atribui um ar de aparência, em face dos seus múltiplos mecanismos ditatoriais "sistemáticos e programados" de produção e venda de "bens culturais com o objetivo precípuo de maximizar o lucro, a comercialização em grande escala, transformando, por isso, os bens culturais em bens de consumo. Pois, de outra maneira, não há como esquivar-se de sua teia enganadora e, ideologicamente, repressora. "No trajeto da mitologia à logística, o pensamento perdeu o elemento da reflexão sobre si mesmo, e hoje a 
maquinaria mutila os homens mesmo quando os alimenta" (ADORNO; HORKHEIMER, 1985, p. 48). Por isso, urge que todos os esforços sejam multiplicados no sentido de se educar para o esclarecimento e para a emancipação. "Uma democracia efetiva só pode ser imaginada enquanto uma sociedade de quem é emancipado" (ADORNo, 1995, p. 145).

No texto "Educação e Emancipação" (1995), escrito para um debate na Rádio de Hessen, que foi transmitido em 13 de agosto de 1969, Adorno, referendando-se em Kant, expõe que a educação só tem sentido se ela for desenvolvida no sentido de livrar as pessoas do tutelamento, isto é, do seu estado de menoridade, o qual é responsável por fazer com que a pessoa permaneça à deriva do esclarecimento. $\mathrm{E}$ em que consiste o esclarecimento para Kant (2005):

Esclarecimento [Aufklärung] é a saída do homem de sua menoridade, da qual ele próprio é o culpado. A menoridade é a incapacidade de fazer uso de seu entendimento sem a direção de outro indivíduo. 'O homem é o próprio culpado dessa menoridade se a causa dela não se encontra na falta de entendimento, mas falta de decisão e coragem de 'servir-se de si mesmo' sem a direção de outrem. Sapere aude! Tem coragem de fazer uso de teu próprio entendimento, tal é o lema do esclarecimento [Aufklärung] (KANT, 2005, p. 63-64; grifos no original)

Para este filósofo, a falta de esclarecimento deriva, principalmente, da "preguiça", bem como da "covardia" daquelas pessoas que, não obstante tenham sido libertadas da natureza, ainda, contentam-se em permanecer sob o comando de outrem. Na sua perspectiva, o comportamento de dependência deve ser confrontado na sua raiz, porque ele redunda em consequências nefastas para a conquista do esclarecimento, pois, contraditoriamente, as pessoas, sob o jugo da dependência, ao invés de conquistarem a autonomia, pelo contrário, elas se curvam para o reino da heteronomia, mediante a utilização do pensamento mecânico, que é originário dos preceitos e fórmulas, os quais, na visão de Kant (2005, p. 64), configuram-se nos "[...] grilhões de uma perpétua menoridade".

Disso, pode-se inferir que a liberdade, considerada por Kant (2005) como a mais expressiva "pedra de toque da verdade", de bona fide, ou, de outra 
maneira, de "bom grado", é confiada aos responsáveis pela arquitetura da sociedade capitalista administrada. Em decorrência disso, a capacidade de o sujeito autodeterminar-se, por meio do uso autônomo de sua razão, sucumbe-se em favor daqueles que o mantêm sob o seu controle, ou seja, sob o seu aparato dominador. Nesse sentido, não são somente as "qualidades", conforme asseveram Adorno; Horkheimer (1985), que são diluídas por essa lógica técnico-científica, integradora e imediatista, mas os homens, de uma forma geral, são arrebatados por ela. Isso pode ser melhor compreendido na elucidação a seguir:

Não há nenhum ser no mundo que a ciência não possa penetrar, mas o que pode ser penetrado pela ciência não é o ser. É o novo, segundo Kant, que o juízo filosófico visa e, no entanto, ele não conhece nada de novo, porque repete tãosomente o que a razão já colocou no objeto [...] Sujeito e objeto tornam-se ambos nulos [...] $\mathrm{Na}$ redenção do pensamento a uma aparelhagem matemática está implícita a ratificação do mundo como sua própria medida. $\mathrm{O}$ que aparece como triunfo da racionalidade objetiva, a submissão de todo ente ao formalismo lógico, tem por preço a subordinação obediente da razão ao imediatamente dado (ADORNO; HORKHEIMER, 1985, p. 38).
Confirma-se, assim, que o homem, ao romper com o mito e eleger a razão como fundamento das verdades buscadas por ele, autodeterminando-se na ciência, pressupôs haver encontrado a diretriz para a solução dos problemas existentes nas sociedades pré-capitalistas. Entretanto, paradoxalmente, tal como explicita Adorno; Horkheimer (1985), a combinação de ardil e razão conduziu-o a resvalar na sua própria ruína. $\mathrm{O}$ que parecia ensejar realização, libertação, culmina por direcioná-lo à alienação, marxianamente expressando, uma vez que este é conduzido ao estranhamento no tocante aos produtos de sua atividade, às instituições sociais e, também, à cultura (MARX, 2010).

Com efeito, essa perspectiva ideológica criticada de forma contundente por Marx (1988), em virtude de ela minar não apenas as relações do homem com a natureza mas, ainda, as relações humanas, paradoxalmente, ao contrário de autonomizar o espírito, reitera-se, levou à regressão da subjetividade para conformá-la à maquinaria da padronização social, consequentemente, transformando-se em um embuste. 
Quanto mais complicada e mais refinada a aparelhagem social, econômica e científica, para cujo manejo o corpo já há muito foi ajustado pelo sistema de produção, tanto mais empobrecidas as vivências de que ele é capaz [...] Pela mediação da sociedade total, que engloba todas as relações $e$ emoções, os homens se reconvertem exatamente naquilo contra $\mathrm{o}$ que se voltara a lei evolutiva da sociedade, o princípio do eu: meros seres genéricos, iguais uns aos outros pelo isolamento na coletividade governada pela força (ADORNO; HORKHEIMER, 1985, p. 47).

Entende-se que é exatamente contra essa força com pretensão de onipotência que a educação deve resistir de forma implacável, buscando desmistificar a realidade abstrata na qual o sujeito se encontra em face desse contexto opressor $e$ responsável, em grande medida, não somente pela violação de sua liberdade, mas, sobretudo, de sua autonomia. Para Adorno (1995):

[...] é preciso começar a ver efetivamente as enormes dificuldades que se opõem à emancipação nesta organização do mundo [...] O motivo evidentemente é a contradição social; é que a organização social em que vivemos continua sendo heterônoma, isto é, nenhuma pessoa pode existir na sociedade atual realmente conforme suas próprias determinações; enquanto isto ocorre, a sociedade forma as pessoas mediante inúmeros canais $e$ instâncias mediadoras, de um modo tal que tudo absorvem $e$ aceitam nos termos desta configuração heterônoma que se desviou de si mesma em sua consciência (ADORNO, 1995, p. 181).

Ora, como se pensar na possibilidade da realização de experiências formativas diante de uma realidade cuja configuração é heterônoma? Por isso, compreende-se que emerge para a educação a tarefa premente de ela envidar todos os esforços no sentido de confrontar, por meio do esclarecimento, todos os elementos que vêm possibilitando a multiplicação dos mecanismos de separação entre os seres humanos, principalmente, no que tange à divisão mais relevante, que diz respeito à cisão entre "[...] trabalho físico $e$ intelectual" (ADORNO, 1995, p. 164), retirando dos "[...] homens a confiança em si e na própria cultura" (Idem, p. 164). Hoje o combate aos inúmeros processos de barbarização da cultura, tais como: da violência, do genocídio, do racismo, da destruição da natureza, enfim, da debilitação da subjetividade, em virtude da ampliação da racionalidade técnica, tornou- 
se condição indispensável para a superação da tendência, pelo homem, à autodestruição. Pois, segundo a perspectiva adorniana, "[...] a tentativa de superar a barbárie é decisiva para a sobrevivência da humanidade" (ADORNO, 1995, p. 156).

\section{Considerações Finais}

No Ensaio denominado "Resposta à Pergunta: que é 'Esclarecimento'? (Aufklärung)", Kant (2005, p. 69) interroga: "[...] vivemos agora em uma época 'esclarecida' [aufgeklärten]?” E, em seguida, responde: "[...] não, vivemos em uma época de esclarecimento [Aufklärung]". Depreende-se, a partir desta afirmação que a questão emancipatória para o sujeito moderno está relacionada à ideia do devir. Isso significa que Kant "[...] determinou a emancipação de um modo inteiramente consequente, não como uma categoria estática, mas como uma categoria dinâmica, como um vir-a-ser e não um ser" (ADORNO, 1995, p. 181).

Ora, dirigindo-se o pensamento para a realidade sócio-histórica, verifica-se que o horizonte do devir exposto por Kant (1995), conforme já se refletiu até aqui, tornou-se um engodo. Tal realidade é captável ao deparar-se com a sucumbência do sujeito frente ao objeto, em face da excessiva objetivação na qual as sociedades modernas embrenharam-se, minando, dessa forma, a possibilidade de o sujeito galgar a sua liberdade, mediante o exercício da autonomia, conquistando, assim, a sua emancipação. Retomando-se a questão kantiana acima referida, pode-se deduzir que é justamente por isso que Kant (2005) assevera que se vivencia, na modernidade, uma época esclarecida e não, conforme o ideário iluminista, a emancipação.

Não obstante Adorno reconheça que a ideia da emancipação ainda permaneça, por um lado, abstrata, $e$, por outro, segundo Kant (2005), vinculada ao prisma do devir, portanto, revestida da ótica dialética, na visão deste teórico frankfurtiano, a perspectiva emancipatória "[...] precisa ser inserida no pensamento $e$ também na prática educacional" (ADORNO, 1995, p. 143). Na sua concepção, somente voltando-se para o homem, no sentido de instigá-lo ao exercício da liberdade de pensar é que, adornianamente expressando, este homem poderá desenvolver uma "consciência verdadeira". Para Adorno (1995), 
[...] aquilo que caracteriza propriamente a consciência é o pensar em relação à realidade, ao conteúdo - a relação entre as formas e estruturas de pensamento do sujeito e aquilo que este não é. Este sentido mais profundo de consciência ou faculdade de pensar não é apenas o desenvolvimento lógico formal, mas ele corresponde literalmente à capacidade de fazer experiências. Eu diria que pensar é o mesmo que fazer experiências intelectuais. Nesta medida e nos termos que procuramos expor, a educação para a experiência é idêntica à educação para a emancipação (ADORNO, 1995, p. 151).

Daí insistir-se na ideia de a Educação impor-se frente aos processos de enrijecimento do espírito orquestrados de maneira astuciosa e cega pela racionalidade objetiva, cerceadora da liberdade humana, porquanto redutora do pensamento crítico, consoante Marcuse (1967), à lógica do pensamento "unidimensional".

O pensamento unidimencional é sistematicamente promovido pelos elaboradores da política $e$ seus provisionadores de informação em massa [...] A 'finura da razão' funciona, como frequentemente fez, no interesse dos poderes existentes. A insistência nos conceitos operacional e behaviorista se volta contra os esforços para libertar o pensamento e o comportamento 'da' realidade dada e 'para' as alternativas suprimidas. A Razão teórica e prática e o behaviorismo acadêmico e social se encontram em campo comum: o de uma sociedade avançada que transforma o progresso científico $e$ técnico em instrumento de dominação (MARCUSE, 1967, p. 3435).

Este diagnóstico estarrecedor acerca do projeto societário erigido pelo homem moderno, metaforicamente, assemelha-se ao mito de Pandora na antiguidade grega, que, ao abrir a caixa deixou escapar todos os males nela contidos, porém, ao fechá-la permanecera lá no fundo a esperança (BRANDÃo, 2013). Mas, se, por um lado, o mito explica a realidade, deixando entrever que as promessas eleitas por tal racionalidade foram ofuscadas pelos males que ela espalhou, por outro, esse mesmo mito, ao explicar a realidade, pode ensejar a possibilidade de se vislumbrar a esperança de confrontação a tal paradoxo. E é justamente aí nesse veio que se encontra a Educação. Para tanto, compreende-se que tal processo de esclarecimento deve iniciarse, em primeiro lugar, por perscrutar de onde derivam os mecanismos de condução dos sujeitos à incapacidade de realização de experiências. A problemática mais preocupante com que se depara 
[...] atualmente consiste em que os homens não são mais aptos à experiência, mas interpõem entre si mesmos $e$ aquilo a ser experimentado aquela camada estereotipada a que é preciso se opor. [...] Uma educação efetivamente procedente em direção à emancipação frente a esses fenômenos não poderia ser separada dos questionamentos da psicologia profunda (ADORNO, 1995, p. 148-149).

A Psicanálise freudiana investigou as raízes de onde procede a tendência que foi se generalizando na cultura moderna, levando-a a centrar-se no "princípio do prazer", pela rendição da consciência aos instintos primários, causando, por conseguinte, a fragilização da subjetividade. Contra esse processo de barbarização compreende-se que emerge para a educação, segundo Adorno (1995), a urgência de ela examinar todos os efeitos causados pela técnica tanto na "consciência" como no "inconsciente" do indivíduo, a fim de estabelecer o rompimento com todos os "[...] mecanismos de repressão", bem ainda com todas aquelas "[...] formações reativas que

\footnotetext{
${ }^{3}$ No tocante ao trabalho da Psicanálise, sugere-se que seja consultado o texto "Além do Princípio do Prazer" (2010).
}

deformam nas próprias pessoas sua aptidão à experiência” (ADORNO, 1995, p. 150).

Em segundo e último lugar, entendese que é preciso que se atente para o fato de que a Educação sob o prisma emancipatório, para além do "compromisso", exige que a atenção por parte do sistema educativo tenha como ponto de partida a infância, buscando confrontar os múltiplos processos de aprisionamento das subjetividades pelas teias racionalizadas tecnicamente do "mundo administrado". E, além disso, é necessário que se busque o "[...] esclarecimento geral, que produz um clima intelectual, cultural e social", segundo Adorno (1995, p. 123), que não possibilite a reedição da barbárie, conforme ocorreu com Auschwitz. Infere-se que isso somente será viável se se estabelecer "[...] um clima em que os motivos que conduziram ao horror tornem-se de algum modo conscientes" (Idem, p. 123).

Por isso, mais do que nunca, tornase urgente a educação para o esclarecimento, com vistas à resistência à heteronomia, isto é, ao tutelamento, de acordo com Kant (2005). Isso significa que a educação deve inclinar-se para o desenvolvimento de conteúdos 
emancipatórios, que propiciem uma formação ampla, contemplando conteúdos não somente ligados às ciências, mas, sobretudo, aqueles relacionados à estética, à ética e à humanização, buscando, dessa forma, privilegiar uma categorização não "estática", mas "dinâmica", consoante Adorno depreende-se do sentido de emancipação kantiano. Enfim, entende-se que este é o significado que se quer atribuir à formação para a emancipação.

\section{REFERÊNCIAS}

ADORNO, Theodor W. "La actualidad de la filosofia". In: Actualidad de la filosofia. Barcelona: Paidós Ibérica: Instituto de Ciências de la Educación: Universidad Autónoma de Barcelona, 1991 a, p. 73-102 (Colección Pensamiento Contemporáneo; v. 18).

. "La ideia de historia natural". In: Actualidad de la filosofia. Barcelona: Paidós Ibérica: Instituto de Ciências de la Educación: Universidad Autónoma de Barcelona, 1991 b, p. 103-134 (Colección Pensamiento Contemporáneo; v. 18).

- Educação e emancipação. Trad. Wolfgang Leo Maar. Rio de Janeiro: Paz e Terra, 1995.

- Escritos sociológicos I. Madrid: Akal, 2004 (Obra Completa; v. 8).

Dialética negativa. Trad. Marco

Antônio Casanova. rev. téc. Eduardo
Soares Neves Silva. Rio de Janeiro: Jorge Zahar, 2009.

ADORNO, Theodor W.; HoRKHEIMER, Max. Dialética do esclarecimento: fragmentos filosóficos. Trad. Guido Antonio de Almeida. Rio de Janeiro: Jorge Zahar, 1985.

BENJAMIN, Walter. "Experiência e pobreza". In: Magia, técnica, arte e política. Trad. Sérgio Paulo Rouanet. 7. ed. São Paulo: Brasiliense, 1994. (Obras Escolhidas; v. 1).

BotTOMORE, Tom. Dicionário do pensamento marxista. Trad. Wantensir Dutra. 2. ed. Rio de Janeiro: Zahar, 2012.

BRANDÃO, Junito de Souza. Mitologia grega. 25. ed. Petrópolis: Vozes, v. 1, 2013.

FREUD, Sigmund. "Além do princípio do prazer (1920)". In: . História de uma neurose infantil ("o homem dos lobos"): além do princípio do prazer e outros textos (1917-1920). São Paulo: Companhia das Letras, 2010, p. 161-239 (Coleção Obras Completas; v. 14).

HORKHEIMER, Max. "Teoria tradicional e teoria crítica". In: ADORNO, Theodor W.; HORKHEIMER, Max. Textos escolhidos. Trad. Zeljko Loparić et al. 5. ed. São Paulo: Nova Cultural, 1991a. p. 31-68 (Coleção Os Pensadores; v. 16).

"Filosofia e teoria crítica". In: ADORNO, Theodor W.; HORKHEIMER, Max. Textos escolhidos. Trad. Zelko Loparić et al. 5. ed. São Paulo: Nova Cultural, 1991b. p. 69-75.

KANT, Immanuel. Crítica da razão pura. Trad. Valerio Rohden e Udo Baldur Moosburger. São Paulo: Nova Cultural, 1996. (Coleção Os Pensadores). 
. "Resposta à pergunta: o que esclarecimento (Aufklärung)?" In: Textos seletos. Trad. Floriano de Sousa Fernandes. 3. ed. Petrópolis: Vozes, 2005, p. 63-71

LAPLANCHE, Jean; PONTALIS, Jean-Bertrand. Vocabulário da psicanálise. 4. ed. Trad. Pedro Tamen. São Paulo: Martins Fontes, 2001.

MARCUSE, Herbert. Ideologia da sociedade industrial. Trad. Giasone Rebuá. Rio de Janeiro: Zahar, 1967.

- "Industrialização e capitalismo na obra de Marx Weber". In: Cultura $e$ sociedade. Trad. Wolfgang Leo Maar, Isabel Maria Loureiro, Robespierre de Oliveira. Rio de Janeiro: Paz e Terra, v. 2, 1968. p. 113-136.

MARX, Karl. O capital. Trad. Regis Barbosa e Flávio R. Kothe. 3. ed. São Paulo: Nova Cultural, 1988 (Coleção Os Economistas; v. $1)$.

. Manuscritos econômico-filosóficos. Trad. apres. e notas Jesus Ranieri. São Paulo: Boitempo, 2010.

SCAREL, Estelamaris Brant. Dilemas inerentes ao potencial formativo entre conhecimento e dialética negativa. Goiânia, 2016. 158f. Tese (Doutorado em Educação) - Programa de Pós-Graduação em Educação, Universidade Federal de Goiás.

WEBER, Max. A ética protestante e o espírito do capitalismo. 7. ed. São Paulo: Pioneira, 1989.

Recebido em: 09/03/2018

Aprovado em: 10/04/2018 